\title{
Out-of-Print Digital Scanning
}

\section{An Acquisitions and Preservation Alternative}

\section{Suzanne Kellerman}

This article describes the in-house operational procedures developed at the Penn State University Libraries to produce facsimiles of hard-to-locate, out-of-print $(O P)$ titles using digital scanning technologies. Since the out-of-print scan (OP/Scan) reproduction service was launched in 1995, more than a hundred titles have been added to the libraries' circulating collections. This process, a collaborative effort by the Acquisitions Services Department, the Preservation Department, the Office of Interlibrary Loan, and the University's Office of Copyright Clearance, has enabled the libraries to reduce the turnaround time for acquiring $O P$ titles from years to only several months. Operational procedures developed by the four library units, including identification and selection, copyright considerations, materials preparation, scanning, and associated costs are described.

Tistorically, tracking down elusive out-of-print (OP) titles could be a time1 consuming and often frustrating endeavor for most libraries. The process to locate and acquire an OP title often could take from several months to more than a year. In some cases, the OP search remained an "active want" and languished in a library's acquisitions workflow for literally years as an open search. However, the advent of new digital technologies, the development and evolution of the Web, and the increased availability of Web-based and Internet sources has dramatically changed the ways in which libraries acquire these hard-to-find OP titles. A published report by Steve Johnson on the Association for Library Collections and Technical Services (ALCTS) Out-of-Print Discussion Group meeting at the 1998 ALA Midwinter Meeting attests to the impact of these new trends:

The OP market, for years a bastion of high markup and low sales volumes, has been turned on its head. Low markup and high sales are the watchwords of the day. In pre-Internet times, many people did not attempt to search for OP books due to the slow, expensive, and cumbersome nature of the business. But the Internet has changed all of that. Locating OP "wants" is now quick, easy and inexpensive (Johnson 1998, 370-71).

Additionally, results from a 1999 survey published in Against the Grain on the use of out-of-print searching on the Web confirmed that the trend is definitely to use the Web, especially when trying to locate domestic titles (Fennessy, Albright, and Miraglia 1999). The survey discovered that U.S. titles were easier to find than foreign works. 
Another recent trend affecting the OP market is the increased availability and use of print-on-demand (POD) technology. For years, when books went out of print, consumers and libraries had no other recourse but to place their "want list" with an OP vendor or dealer and wait. With new revolutionary advances in the technopublishing business, print-on-demand has become a viable economic option for publishers and libraries alike (Berry 1998; Never Out of Print 1998; Terry 2000; Haugan 2000). Thanks to publisher print-on-demand capabilities coupled with emerging ondemand binding offered by binders (Campbell 1994), no book should have to slip to OP status again. Today, book publishers and companies such as ProQuest Information and Learning Company's Books on Demand, Ingram Industries' Lightning Source, Baker and Taylor's Replica Books, and netLibrary, Inc. will scan and produce single copies of books based on user demand.

While some publishers have only recently begun to offer on-demand books, libraries have had the capability to produce or acquire single facsimiles of books for their collections using traditional xerographic technology (photocopying). Used successfully by libraries for many years, preservation photocopying allows libraries to produce use copies of fragile originals, replace missing or damaged pages, or replace entire books (Walker 1987; Barker, Rottman, and Ng 1990; Orr 1990; Baird 1997). This technique provides the means to preserve the intellectual content of published works that might otherwise be lost. Until recently, the only methods available for creating facsimiles were to generate a black-and-white copy on a photocopying machine and print the image on alkaline paper, or to produce a Copyflo paper copy from microfilm. Now with the advent of digital capture technologies and quality production printing-the successor technology to preservation photocopying-some libraries are embracing digital printon-demand solutions as a new means of acquiring materials, especially hard to locate out-of-print materials.

The advantages of digital imaging over traditional photocopying are profound. Not only does this technology allow for the creation of machine-readable files that can be quickly and easily accessed time and time again, but copies can also be reproduced with $100 \%$ accuracy with no degradation of quality in comparison to the originals, as would be the case with photocopies. In addition, text can be accurately aligned and registered back to front, and sophisticated editing allows for vastly improved image quality.

\section{Background}

Since the inception of the Penn State University Libraries' first digital preservation demonstration project in 1992, the Preservation Department has been actively engaged in using digital scanning to convert existing paper collections to electronic form. Digitization projects to convert sundry and disparate archival collections from Special Collections were the prevailing activities of the scanning unit for the first several years of its existence. Since then, the scanning unit, one of four units in the Preservation Department, has evolved to serve as overseer of digital imaging projects for preservation purposes and as the primary production capture center for the university libraries. Much of the unit's work today consists of creating paper reproductions of brittle books, out-ofprint titles, whole periodical issues, and production of replacement pages. OP title scanning represents $5 \%$ of the unit's weekly production workflow. This unit also provides consultation to library selectors and staff on technical matters regarding digitization projects including materials preparation, image capture, Web site design, and file and server maintenance. Staff also train library personnel in digital capture methods and serve as liaison to library systems personnel. The unit currently employs 2.75 full-time employed staff.

In 1993, while the scanning unit was still in its formative stage, the libraries experienced a major water disaster that resulted in sixty-five thousand damaged volumes, of which more than one hundred were completely unsalvageable. As the library staff worked to recover the vast majority of the water-damaged volumes, library selectors reviewed the one hundred titles deemed unsalvageable and decided that many of these titles should be replaced. Replacement orders were prepared and placed with the Acquisitions Services Department's University Firm Order (UFO) Team for processing. Preliminary searching by the Acquisitions staff revealed that all of these titles were out of print. Orders were placed with OP vendors and the UFO team waited for orders to be filled. After a year, many of these titles still remained "active wants." As alternative replacement solutions were being considered, the idea arose to investigate whether in-house scanning operations could facilitate the process of replacing these lost volumes.

The basic premise was to borrow the needed title from another library location, scan each page from the borrowed volume, print the captured file to permanent paper, send the printed pages for commercial binding, and add the newly created volume to the collection. A pilot project to test the operational procedure-assessing individual unit workflow issues, turnaround time, product quality, and selector satisfaction —was initiated. After minor adjustments were made to streamline the workflow process, the procedures were adopted. Since the OP/Scan reproduction service was officially launched as a new alternative library procedure for acquiring preservation-quality $\mathrm{OP}$ titles in May 1995, more than one hundred titles have been added either as new titles or replacement copies of lost titles. As a result of this new procedure, the university libraries reduced 
the turnaround time for acquiring OP titles from several years to several months and improved the long-term quality of the volumes being added to the collection.

\section{The OP/Scan Process}

The OP/Scan procedure described in this article was the direct result of a collaborative effort among the staffs from the UFO team, the Preservation Department's Digital Scanning Unit, the Interlibrary Loan Borrowing Unit, and the University's Office of Copyright Clearance. The responsibility and workflow activities of each of these four units are described in detail below.

\section{Identification and Selection}

Conducting traditional OP searches and placing order requests with vendors, dealers, and online booksellers remains an integral part of the acquisitions process. The first step in any OP search involves the review of each order submitted by library selectors and the identification of an appropriate vendor by the UFO team. Once a vendor is chosen, an online order record is created for tracking purposes and the order is placed. If the book is found, the vendor ships the book fulfilling the order and the order is complete. If, on the other hand, the order remains unfilled for a period of time, the UFO team reviews the request as a potential $\mathrm{OP} / \mathrm{Scan}$ title. In order for the title to be considered an $\mathrm{OP} / \mathrm{Scan}$ title, it must meet the following selection criteria:

- The requested title must have been placed as an "active want" with a vendor for at least two months. Internally, it was determined that a two-month search by a vendor was an acceptable amount of time for an order request to be fulfilled and that a two-month window demonstrated an ethical "good faith attempt" to try to purchase the title from a vendor or dealer.

- If the library selector initiating the order designated a title as a rush request, it must be placed as an active search with a vendor or dealer for at least one month.

- Due to the size limitations of the in-house scanning systems, the physical dimension of the volume cannot exceed 11" x 17" or $28 \mathrm{~cm} \mathrm{x} 43 \mathrm{~cm}$. Any volume exceeding these dimensions cannot be scanned using the in-house equipment and must be kept on "active want" status.

If it is determined that a requested OP title meets the required selection criteria, the Acquisitions' UFO staff annotates the existing online $\mathrm{OP}$ acquisitions record for the title as an OP/Scan. A copy of the original selector order request including all supplementary bibliographic search results from RLIN or OCLC, along with a completed OP/Scan Request Form, are sent to the Preservation Department for the next step of the process, which is to calculate the estimated cost to have the title scanned, printed, and commercially bound.

\section{The Cost Factor}

Once the completed OP/Scan Request Form and accompanying materials are received in the Preservation Department, staff review the paperwork to estimate the associated costs of producing a paper facsimile of the item. Since library selectors' acquisitions budgets are charged for the reproduction copy, notification of estimated costs and signed approval by the selectors are required before the $\mathrm{OP} / \mathrm{Scan}$ process can continue.

Estimated costs for scanning and quality control inspection (labor costs), printing, binding, and copyright and processing fees are calculated and reported on the OP/Scan Request Form. The completed form is then returned to the UFO team. Data elements found on the bibliographic record, primarily the imprint information found in MARCtag 300 field, are used to estimate the associated costs for scanning, printing, and binding. Calculating the costs to scan a volume is purely speculative without having the book in hand. Costs can vary wildly depending on the physical characteristics of each item. Page size, number of pages, illustrations, photographs, plates, foldouts, and maps are all variable factors that must be taken into consideration when calculating the cost and length of time needed to reproduce an item. On average, per page image costs have ranged from $\$ .13$ to $\$ .39$.

When the UFO team receives the completed OP/Scan Request Form with the estimated costs, the staff prepares and sends an interoffice memo, including estimated costs for scanning, to the library selector outlining options for acquisition of the title in question. The selector is asked to choose one of three options outlined on the form. The options are:

- to continue the title search as an "active want" and retain the order with the vendor or dealer. This selection option is chosen primarily when the selector desires an original publisher's copy.

- to discontinue the search and cancel the order. This option is selected if it is deemed by the selector that the item is no longer needed.

- to have the item borrowed via interlibrary loan and scanned to make a reproduction copy.

Selectors are given three weeks to make a processing decision. After the decision is made, the selector then returns the annotated memo to the UFO team to carry out 
the selection decision. If the selector's decision is to retain the title search as is, the online order record is updated to reflect the decision and the title search remains open as an "active want" with the vendor. If the decision is returned to discontinue the OP search, the online record is updated and the request is canceled with the vendor. If the selector approves the title to be scanned, the UFO team initiates the process to seek copyright permission through the university's Office of Copyright Clearance.

\section{Copyright Issues and Considerations}

Copyright permission may not be required before producing a scanned copy depending on when the work was published or the condition or status of the first purchased copy. Replacement copies for a missing, lost, stolen, damaged, or deteriorating volume may not require copyright permission before a scanned copy is produced if the library determines by reasonable means that a copy cannot be obtained at a fair price. Additionally, published works that are considered in the public domain do not require copyright permission (Gasaway 1999). Copyright permission is pursued if either of these situations applies:

- The library never owned the title and the date the work was published is protected by copyright, or

- The library is requesting a second copy for the same location or different location, i.e., another campus location, and the work is protected by copyright

For Penn State, the university's Office of Copyright Clearance is our authorized source to pursue copyright permission for our OP titles. We rely on this office to carry out the necessary investigative work to find and locate rights holders and seek the necessary permission to reproduce a paper copy of the work. In most cases, we only seek permission to make a single reproduction copy but may on occasion request permission to display the work electronically. Extreme caution is exercised when working with titles clearly not in the public domain and restricted by copyright.

The process of seeking permission from authors, publishers, or rights holders can be an arduous task at best. In some cases, permission is granted within one to three weeks, but more often the process takes several months to a year. The copyright office gives rights holders a window of ten to twelve weeks to respond to a copyright permission inquiry. After that time limit, the office follows up with faxes, emails, and phone calls to elicit a response. Basically, all the office can do is wait for a response. In some cases, the office may never receive a response. Copyright fees vary. To date, the largest fee paid for a single title was \$23.94. In many cases, the authors, publishers, and rights holders were so pleased that the libraries wanted a copy of their work that no fee was charged. In addition to a copyright fee, the copyright office assesses the libraries a processing fee for carrying out the copyright investigation process. This fee is calculated at one cent per page for the entire work, plus phone and fax charges. On average, a typical processing fee is $\$ 20$. For legal purposes, the copyright office maintains a permanent hard copy file of all correspondence with rights holders.

\section{Procurement and Preparation of Materials}

Once permission is granted and permission fees are assessed, the copyright office forwards the permission response to the Acquisitions staff along with the copyright and processing fees.

\section{Interlibrary Loan}

The next step in the process is for the UFO team to initiate an interlibrary loan (ILL) request for the title. Using the OCLC ILL module, the ILL Borrowing Team processes the request. ILL staff annotates the request stating that the entire book is needed and that the title will be electronically scanned. In addition to the note, a contact name and telephone number are given should the lending library have questions about the ensuing process. There are occasions, however, when contacting the collection development librarian or the preservation officer directly is the preferred option when seeking to borrow special types of materials. These include:

- rare books

- books held by very few libraries

- reference materials (requiring special permission)

- books with restricted or limited access

\section{Materials Preparation}

After the title has been borrowed from another institution and delivered to the Preservation Department, scanning unit staff inspect the book to assess its "scannability." Each physical volume is carefully examined for durability, type and condition of leaf attachment, and paper flexibility. Special attention is made to discover if margins are tight, if colored plates exist, if pages are loose, or if there are foldouts. The two-double-fold brittle paper test is conducted to detect paper strength and flexibility. If the volume is too fragile, exceeds the size limit, or has color plates, it is not scannable. The volume is returned to ILL and a new ILL request is initiated. If the volume passes the preservation assessment, it is then prepped and placed in queue for scanning. The volume is collated for completeness; pages 
are counted; special characteristics of the book such as foldouts and plates are noted; and the overall size of the volume is measured. This volume-specific information is recorded on a Digital Processing Form, along with bibliographic data, special handling or reproduction instructions from the lending library, selector notes, copyright restrictions, and the interlibrary loan due date (figure 1).

\section{Production Scanning}

After the volume is collated and prepped, and scanning instructions are reviewed, the production scanning begins. The volume is hand-placed on the flatbed scanner and gently flexed open to accommodate each page scan. Text and line-drawn illustrations are captured as 600 dpi black and white images. Half-tone photographs are generally captured in 600 dpi grayscale. Selective image editing is performed. The main goal in producing a facsimile copy is to make the text and illustrations legible. Images are edited to correct skew, eliminate or reduce print bleedthrough, and remove distracting stains or marks, such as pencil or pen underlining. Margin notes or other markings that obscure the text are also erased. Scanning technicians routinely edit out the lending library's ownership markings, call number, or accession numbering.

Once production scanning is complete, each page image is inspected for quality and compared to the original text page. Using the original text as a guide, the scanning technician reviews images to check for appropriate light-to-dark contrasts of text and to improve image representation after editing. Rescanning is performed as needed to replace poor quality images with improved rescans. Following the often labor-intensive inspection process, page images are electronically transmitted in a batch mode for on-demand two-sided printing. The Xerox DigiPath scanning workstation provides the capture and image production (the only known system that can scan 600 dpi black and white documents at the speed of two to three seconds per page and has the functionality to accurately align text back to front on each page), while the Xerox DocuTech Publication Publisher system provides the printing. The Xerox DigiPath production system coupled with the DocuTech Publisher offers the maximum end-to-end book production needed to produce preservation-quality facsimile reproductions. Page images are printed on $25 \%$ cotton bond, 20-pound alkaline (permanent) paper that complies with the Permanent Paper Standard issued by

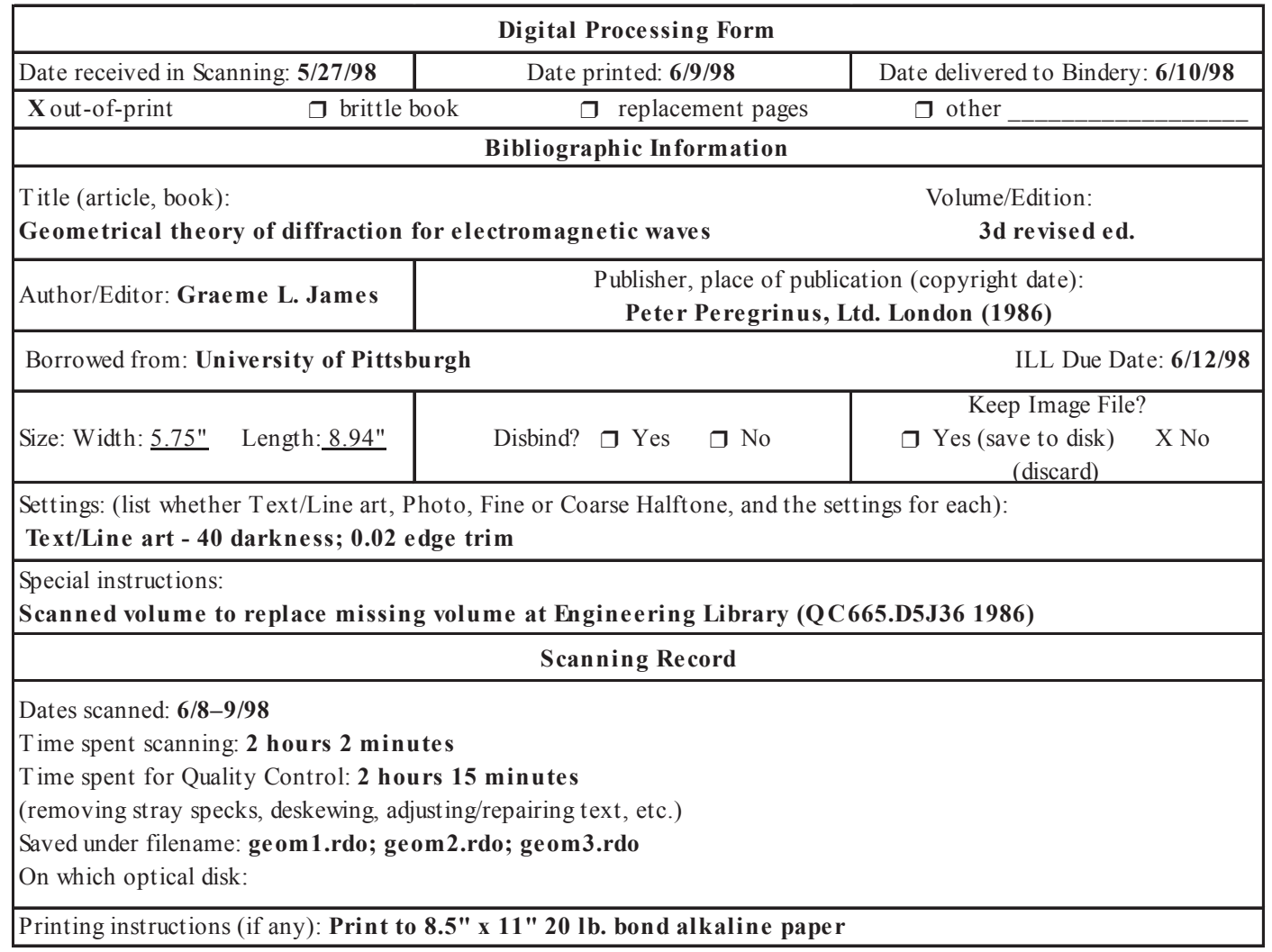

Figure 1. Digital Processing Form Used to Indicate Volume-Specific Characteristics and Instructions to Scanning Technician 
the National Information Standards Organization (Z39.481984). As a final inspection action, each printed page is again compared to the original text pages to ensure quality and accuracy of the facsimile reproduction. When required by the terms of copyright permission, scanning staff delete the page image files from the system.

\section{End-Processing}

After the book is scanned and page images printed, the preservation scanning staff complete the OP/Scan process by reporting the actual book production costs. Costs are based on the time spent on each task involved: materials preparation, scanning, and quality control inspection of images and printed pages. These individual times are multiplied by a pre-established hourly rate. In addition, actual costs for printing and commercial binding are calculated and reported on a Reproduction Cost Sheet (figure 2).

After the cost sheet is completed, printed pages are processed for commercial binding and the original borrowed book is returned to ILL. Before binding, a Notice of Copy Statement is added as the first printed page of the volume to alert users that the volume in hand is a reproduction (figure 3).

In addition to including a Notice of Copy Statement in the physical volume, a MARC-tag 533 field is added to the bibliographic record of the title indicating that the copy is a reproduction. "Scanned" is also noted in the holdings statement to alert patrons that the item is a facsimile (figure 4).

Preservation scanning staff annotate the original OP/Scan Request Form with the cost information, the date scanning was completed, and the date that the reproduction copy was sent for binding. On receipt of the completed OP/Scan form, the Acquisitions staff encumbers the selector's collection development fund for the total cost of the scanned copy, including copyright fees and copyright office processing fees. All original paperwork associated with the $\mathrm{OP} / \mathrm{Scan}$ title acquisition process is delivered to the Preservation Department for permanent retention.

\section{Summary Data}

The OP/Scan process has proven to be a viable solution for obtaining hard-to-locate, out-of-print library materials. The data below provide brief quantitative results of the Penn State University Libraries' six-year experience:

- To date, the Preservation scanning unit has scanned 116 OP titles

- 55 (47\%) have been new titles; each requiring copyright permission prior to scanning

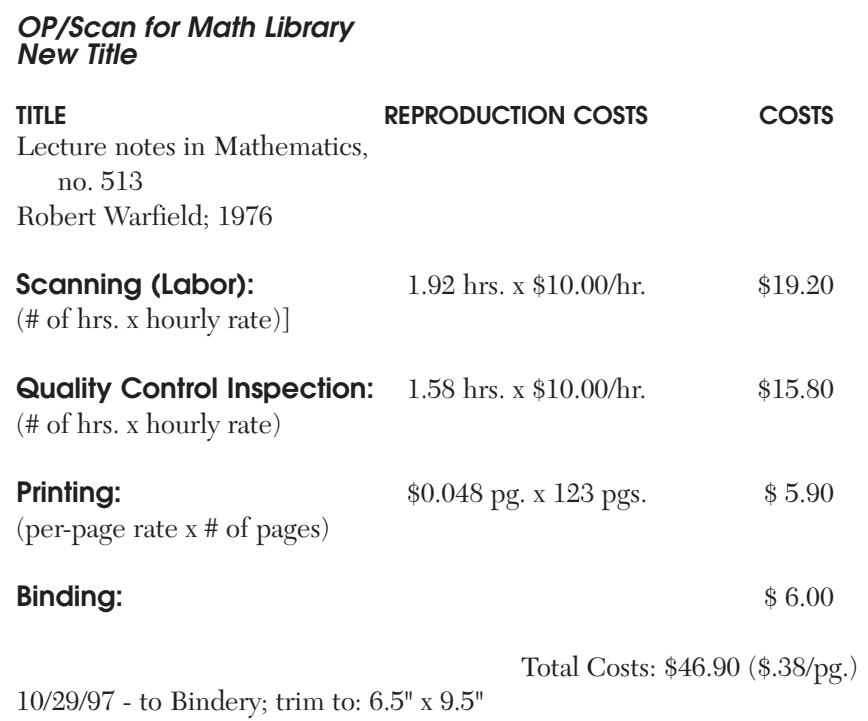

10/29/97 - ILL volume returned

(Paid \$7.50 copyright fee)

Figure 2. Completed Reproduction Cost Sheet Showing Calculated Costs for Scanning, Quality Control Inspection, Printing, and Binding

- 61 (53\%) have been replacement copies of lost volumes

- Average turnaround time for the entire OP/Scan process is two to four months

- Average per-page scanning cost: $\$ .28$

- Average total cost for reproduced OP title: $\$ 63.27$

\section{Future Trends}

Clearly, not every institution is capable or inclined to purchase sophisticated, high-quality scanning and printing equipment. Recognizing the potential market for this service, some commercial binders have begun to diversify their services and now offer reproduction services (Larsen 2000). As commercial binders broaden their service offerings to include bookson-demand and on-demand binding, it will be possible for many libraries to consider these options for replacing OP titles and other reprinting needs. In the September 1999 issue of the New Library Scene, George Cooke noted that this trend could be carried even one step further:

Books, journals and collections of manuscripts will become more accessible and affordable in the near future through automated on-demand binding. But today, digital copies can be produced from archival microfilm, which serves as the source for books-ondemand. Many library customers would prefer to 
The University Libraries at Penn State reproduced this volume, and has done so in compliance with current copyright law. The University Libraries produced this volume using digital technology, and the copy has been printed on paper that complies with the Permanent Paper Standard issued by the National Information Standards Organization (Z39.48-1984)

[date]

Figure 3. A Notice of Copy Statement is Added to Each Facsimile Reproduction to Alert Users That the Volume in Hand Is a Reproduction

\begin{tabular}{|c|c|c|}
\hline \multicolumn{2}{|l|}{008} & ENT: 810316 TYP: s DT1: 1970 DT2: LAN: eng \\
\hline \multicolumn{2}{|l|}{010} & 70132918 \\
\hline \multicolumn{2}{|l|}{019} & MARS \\
\hline \multicolumn{2}{|l|}{040} & $\$ c P S t \$ d W a O L N$ \\
\hline 050 & 0 & TN871 \$b.F28 \\
\hline \multicolumn{2}{|c|}{090} & TN871 \$b.F28 \$cem+(scanned) 32906264 \\
\hline 100 & 2 & Farouq Ali, S. M., \$d1936- \\
\hline \multirow{2}{*}{$\begin{array}{l}245 \\
260\end{array}$} & 10 & Oil recovery by steam injection / $\$ \mathrm{c}[\mathrm{by}] \mathrm{S}$. M. Farouq Ali. \\
\hline & & Bradford, Pa. : \$bProducers Pub. Co., $\$ c 1970$. \\
\hline \multicolumn{2}{|l|}{300} & vi, 122 p. : \$billus., maps. ; $\$ \mathrm{c} 28 \mathrm{~cm}$. \\
\hline \multirow{2}{*}{\multicolumn{2}{|c|}{500}} & "The present book is a compilation of selected articles written \\
\hline & & hor for the "Producers Monthly". \\
\hline \multicolumn{2}{|l|}{504} & Includes bibliographical references. \\
\hline \multicolumn{2}{|l|}{533} & Reproduction (printout). \$bUniversity Park, Pa., \$cThe \\
\hline \multicolumn{3}{|c|}{$\begin{array}{l}\text { Pennsylvania State University, } \$ d 1998 . \$ n E \& M S \text { copy reproduced } \\
\text { from computerized image files. }\end{array}$} \\
\hline 650 & & 0 Thermal oil recovery. \\
\hline
\end{tabular}

TN871.F28

Earth \& Min Sci Library, 105 Deike-

Item (scanned)

1 Available

Figure 4. Online Catalog Record Showing MARC-tag Field and Holdings Statement Alerting Patrons That the Item Is a Reproduction

have an exact copy printed on good paper and in a sturdy binding rather than reading the text from a reel of microfilm. The combination of computers, digital technology and automated bindery equipment offers exciting prospects for the future. It has been possible for quite a few years to order relatively inexpensive photocopies from stored microfilm, but nothing we have known in the past can equal the promise offered to binders by the new technology (18-19).

\section{Conclusion}

With the unprecedented explosion of information technology and subsequent round-the-clock online access to books, journals, and other information sources, it is increasingly difficult to justify an eighteen- to twenty-four-month delay in securing OP materials requested by faculty and students. Expectations of "instant delivery" have been raised, and such a time lapse has become unacceptable to researchers and scholars. Compounding the problem is the fact that publishers no longer maintain expensive warehouses with vast stores of books that may never be requested; hence, titles become out-of-print more rapidly and with far greater frequency than was previously the case. The University Libraries identified this situation as a problem to be solved and initiated the scanning process described in this article.

Since its inception in 1995, the University Libraries' $\mathrm{OP} / \mathrm{Scan}$ process has proven to be a cost-effective and process-efficient alternative for acquiring hard-to-locate OP titles. Because the University Libraries had the necessary equipment and network connectivity already in place (the Xerox DigiPath scanning workstation in-house and the Xerox DocuTech Publication Publisher located across campus at Document Services), it was possible to conceive and implement this innovative solution. As a result, the process has significantly reduced the turnaround time for acquiring OP titles and has provided a viable method for creating a high-quality preservation product for the libraries' collections.

Until commercial vendors routinely offer these services at a competitive price, academic libraries can much more quickly and efficiently fill gaps in their collections by utilizing the OP scanning/binding process. As indicated above, once the process is in place, the reproduction cost per volume is extremely reasonable. Large libraries with the necessary equipment and staff resources should seriously consider this practical approach to collection building and devote a portion of their resources to fulfilling this growing and as yet unmet need.

\section{Works Cited}

Baird, Brian. 1997. Brittle: Replacing embrittled titles cooperatively. College and Research Libraries News 58 (Feb.): 83-84, 95.

Barker, Joseph W., Rebecca A. Rottman, and Marilyn Ng. 1990. Organizing out-of-print and replacement acquisitions for effectiveness, efficiency, and the future. Library Acquisitions: Practice and Theory 14: 137-63.

Berry, John N. 1998. Opening the library treasure chest: Books-ondemand technology for libraries. Library Journal 123(14): 102.

Campbell, Gregor R. 1994. Binding on demand. New Library Scene 13(2): 5-6.

Cooke, George W. 1999. Jack Bendror: Bindery automation pioneer. New Library Scene 18(3): 18-19.

Fennessy, Eamon T., Linda Albright, and Kathy Miraglia. 1999. On the street-out of print searching on the World Wide Web. Against the Grain 11(2): 62, 64. 
Gasaway, Laura N. 1999. When works pass into the public domain. University of North Carolina, Chapel Hill. Accessed September 2000, www.unc.edu/ unclng/public-d.htm.

Haugan, Stephanie. 2000. Leaping to on-demand production. Publishers Weekly (Apr.): S8-9.

Johnson, Steven D. 1998. Needle in the bookstack: Web solutions for finding out-of-print titles. Library Acquisitions 22(3): $370-71$.

Larsen, James M. 2000. President's corner. New Library Scene 19(1): 5
Never out of print. 1998. Publishers Weekly 245 (June): S8-9.

Orr, Gloria J. 1990. Preservation photocopying of bound volumes: An increasingly viable odd. Library Resources and Technical Services 34(4): 445-54.

Terry, Ana Arias. 2000. Innovations-books on-demand: The Lightning Print Story; on demand printing and distribution offer book publishers an alternative business model. Against the Grain 12(1): 71-72.

Walker, Gay. 1987. Preservation decision-making and archival photocopying. Restaurator 8(1): 40-51. 